\title{
Reducing the Excessive Evaporative Demand Improved the Water-use Efficiency of Greenhouse Cucumber by Regulating the Trade-off between Irrigation Demand and Plant Productivity
}

\author{
Dalong Zhang ${ }^{1}$ \\ College of Horticultural Science and Engineering, Shandong Agricultural \\ University, Tai'an, Shandong Province, PR China; and Scientific Observing \\ and Experimental Station of Environment Controlled Agricultural \\ Engineering in Huang-Huai-Hai Region, Ministry of Agriculture, China \\ Yuping Liu \\ Lanao Biotechnology Co., Ltd., Jinan, Shandong Province, PR China
}

Yang Li and Lijie Qin

College of Horticultural Science and Engineering, Shandong Agricultural University, Tai'an, Shandong Province, PR China

\section{Jun Li}

Weining Agricultural Investment Co., Ltd., Bijie, Guizhou Province, PR China

\section{Fei Xu}

Department of Plant Science and Technology, Shanghai Vocational College of Agriculture and Forestry, Shanghai, PR China

Additional index words. greenhouse, vapor pressure deficit, stomatal conductance, photosynthesis, water-use efficiency

\begin{abstract}
Although atmospheric evaporative demand mediates water flow and constrains water-use efficiency (WUE) to a large extent, the potential to reduce irrigation demand and improve water productivity by regulating the atmospheric water driving force is highly uncertain. To bridge this gap, water transport in combination with plant productivity was examined in cucumber (Cucumis sativus L.) grown at contrasting evaporative demand gradients. Reducing the excessive vapor pressure deficit (VPD) decreased the water flow rate, which reduced irrigation consumption significantly by $16.4 \%$. Reducing excessive evaporative demand moderated plant water stress, as leaf dehydration, hydraulic limitation, and excessive negative water potential were prevented by maintaining water balance in the low-VPD treatment. The moderation of plant water stress by reducing evaporative demand sustained stomatal function for photosynthesis and plant growth, which increased substantially fruit yield and shoot biomass by $20.1 \%$ and $18.4 \%$, respectively. From a physiological perspective, a reduction in irrigation demand and an improvement in plant productivity were achieved concomitantly by reducing the excessive VPD. Consequently, WUE based on the criteria of plant biomass and fruit yield was increased significantly by $43.1 \%$ and $40.5 \%$, respectively.
\end{abstract}

Water shortage is the bottleneck for sustainable agricultural production, particularly in semiarid regions. An abrupt decline in the supply of irrigation water to farmers has aroused growing concern, and irrigation management has shifted from emphasizing

Received for publication 11 Apr. 2018. Accepted for publication 14 June 2018.

${ }^{1}$ Corresponding author. E-mail: zd1880626@sdau. edu.cn. the production per unit area toward maximizing the production per unit of water consumed (Deng et al., 2006). From classic views of physics, water transport along the soil-plant-atmosphere continuum is a passive process driven by gradients of free energy. The driving force for water movement is determined by the water potential gradient in the liquid phase (from soil to leaf) and the difference in VPD along the gas phase (from the internal leaf to the atmosphere) (Fricke, 2016; Wheeler and Stroock, 2008).
Regulation of the soil water status has long been recognized as a useful way to improve WUE. Water-saving irrigation techniques such as controlled, alternate partial rootzone irrigation and deficit irrigation have been widely applied for crop production as a result of the reduced water supply without a significant yield reduction (Gheysari et al., 2017; Kang and Zhang, 2004; Yang et al., 2017). Although atmospheric VPD mediates water flow and constrains water productivity to a large extent, regulation of the atmospheric water driving force receives far less attention from growers. The potential to reduce plant irrigation consumption and improve WUE by regulating the atmospheric driving force is highly uncertain.

The increasing sophistication of controlledenvironment agriculture facilitates atmospheric environmental regulation (Katsoulas et al., 2001). Because VPD is an indicator of the atmospheric driving force for water movement, greenhouse operations are moving toward controlling evaporative demand according to VPD (Lu et al., 2015; Zhang et al., 2015). Previous studies have suggested that greenhouse VPD regulation can maintain optimal ranges of temperature and relative humidity (RH) simultaneously, and therefore effectively enhance plant photosynthesis and growth $(\mathrm{Lu}$ et al., 2015; Zhang et al., 2015, 2017, 2018). It is generally considered that the movement of water through the soil-plant-atmosphere continuum is driven by a gradient in water potential in the liquid phase (from soil to leaf apoplast) and a difference in the water vapor pressure in the gas phase (from leaf to atmosphere). Therefore, VPD control was hypothesized to perform significant roles in reducing irrigation demand and moderating plant water stress, which would enhance plant photosynthesis and improve WUE. Cucumber is one of the major vegetable crops cultivated under greenhouse conditions and is considered one of the most important economic vegetables. Cucumber plants require large amounts of water, especially during the flowering and fruiting periods, as the water content of fruit exceeds $90 \%$. Despite the existence of information about the effect of soil moisture on irrigation water demand, few studies have focused on examining the relationship between VPD and irrigation water demand in greenhouse cucumber production. The current study provided innovative practices in saving water consumption and improving WUE in greenhouse cucumber production. The processes of carbon gain and water consumption were coupled to fill the gap between VPD regulation and WUE in greenhouse cucumber production.

\section{Materials and Methods}

Plant materials and growth conditions. Experiments were conducted in two outdoor chambers with similar characteristics (length, $10 \mathrm{~m}$; width, $5 \mathrm{~m}$; height, $3.5 \mathrm{~m}$ ) during the spring-summer seasons from April to July. The variability in environmental factors 
between the two chambers was examined before the experiments. No significant differences in environmental factors were observed between the two chambers. The roof ventilation systems in the two treatments were activated when the temperature inside exceeded the optimum range for cucumber growth.

Cucumber (cv. Jinyou) plants were transplanted at the four-leaf stage and grown in white pots (diameter, $40 \mathrm{~cm}$; height, $30 \mathrm{~cm}$ ). One plant was grown in each pot, and each pot was filled with the same amount of garden mix substrate containing an organic substrate:perlite mixture $(3: 1)$. The planting density was four plants per $\mathrm{m}$. All axillary shoots were removed, and fruit pruning was carried out to leave only a single fruit per node.

The soil surface was covered with a circular polythene sheet to prevent soil water evaporation. Plant transpiration was measured by a standardized gravimetric approach of daily pot weighing with an electronic balance, as described in previous research (Kadam et al., 2015). Excluding soil evaporation, the difference between pot weighing can be considered the plant-transpired water consumption. Soil moisture was maintained uniformly at $85 \%$ to $90 \%$ of field capacity by adding the exact amount of water needed to bring back the moisture content to the desired target.

Experimental design. Two environmental chambers were controlled to have the same growth conditions but a contrasting VPD. A high VPD was maintained in natural conditions without environmental regulation; a low VPD was achieved by artificial humidification when evaporative demand exceeded the optimal range. In the low-VPD compartment, humidification was controlled using a fogging system (spray pressure, 2-6 MPa; droplet size, $25.8-46.2 \mu \mathrm{m}$ ) with a binary fluid mist nozzle. Spraying was activated automatically when the greenhouse VPD exceeded $1.5 \mathrm{KPa}$, which is the recommend value for horticultural crops (Bakker, 1990; Iraqi et al., 1995). The fogging system operated continuously and was turned off when VPD decreased to less than the set point. A randomized complete block design was adopted.

Environmental measurements. Air temperature, relative humidity $(\mathrm{RH})$, and light intensity were monitored by sensors (ZDR20j; WuGe Instruments Co., Ltd., China) installed $\approx 2.5 \mathrm{~m}$ above the ground in the center of each greenhouse. VPD was calculated from $\mathrm{Ta}$ and $\mathrm{RH}$.

Measurements of leaf gas exchange. Leaf gas exchange parameters were measured with a portable photosynthesis system (LI6400; LI-COR Inc., Lincoln, NE) $\approx 40 \mathrm{~d}$ after transplanting (from 0900 to $1200 \mathrm{HR}$ ). All samples were the youngest and fully expanded leaves at the same nodes of the plants. Three leaves per plant were sampled for the measurements. The environmental conditions in the leaf chamber were set close to the open-field conditions in the greenhouse.
The diurnal changes in plant transpiration rate were determined by weighing the pots hourly. The plant transpiration rate was calculated as the ratio of the pot weight change vs. the time between two weighings.

Determination of the net photosynthetic rate and stomatal conductance $\left(g_{\mathrm{S}}\right)$ was repeated with 10 plants in each treatment, and a total of three measurements per plant were performed after steady state and equilibration were attained. Two photosynthesis systems were used to enable simultaneous gas exchange measurements. Stomatal limitation (Ls) was estimated according to $\mathrm{Ls}=1-\mathrm{C}_{\mathrm{i}} / \mathrm{C}_{\mathrm{a}}$, where $C_{i}$ is the intercellular carbon dioxide $\left(\mathrm{CO}_{2}\right)$ concentration and $\mathrm{C}_{\mathrm{a}}$ is the ambient $\mathrm{CO}_{2}$ concentration (Duan et al., 2014). Instantaneous WUE (InstWUE) at the leaf scale was calculated as the amount of carbon gain in photosynthesis rate $\left(\mathrm{P}_{\mathrm{n}}\right)$ per unit of water transpired $\left(\mathrm{T}_{\mathrm{r}}\right)$ : InstWUE $=\mathrm{P}_{\mathrm{n}} / \mathrm{T}_{\mathrm{r}}(\mathrm{Xu}$ and Zhou, 2008).

Determination of the plant water status. Leaves were cut off and their fresh weight was measured. To determine the turgid weight, leaves were kept in distilled water in darkness until they reached a constant weight (full turgor, after $24 \mathrm{~h}$ ). The relative water content (RWC) was calculated according to the following equation: $\mathrm{RWC}=($ fresh weight - dry weight)/(turgid weight - dry weight).

After leaves were cut off, the leaf water potential $\left(\Psi_{\text {leaf }}\right)$ was measured immediately using a pressure chamber (PMS1000 Instrument; Corvallis, OR). Measurement of the predawn leaf water potential (predawn $\Psi_{\text {leaf }}$ ) began at about $0430 \mathrm{HR}$ and finished before sunrise. In general, midday leaf water potential (midday $\Psi_{\text {leaf }}$ ) was measured between 1230 and 1330 HR. Stem water potential $\left(\Psi_{\text {stem }}\right)$ was estimated using the baggedsealed leaf technique (Zsögön et al., 2015). Briefly, the opposite leaf near a transpiring leaf was covered with aluminum foil and
High VPD Low VPD

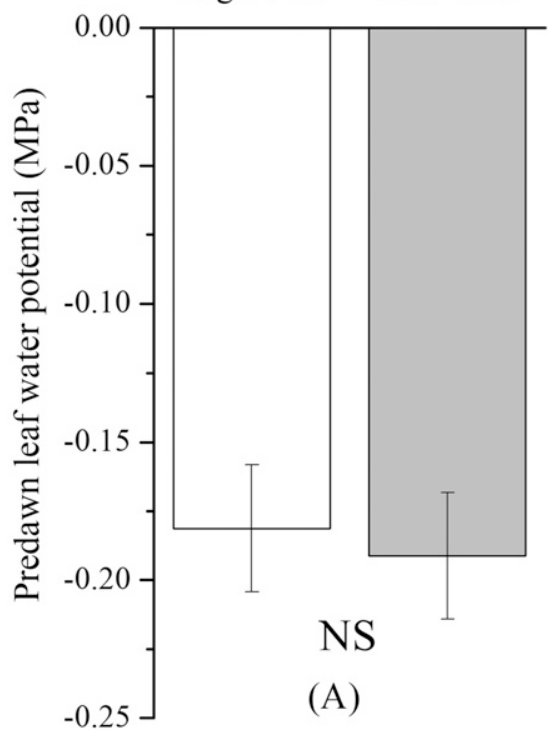

plastic wrap the night before measurement. The pressure potential of the bagged leaf was assumed to provide an estimate of $\Psi_{\text {stem }}$.

The evaporative flux method was applied to estimate midday whole-plant hydraulic conductance $\left(\mathrm{K}_{\text {plant }}\right)$ using the midday parameters of plant water status (Attia et al., 2015; Simonin et al., 2014; Tsuda and Tyree, 2000), including the whole-plant transpiration rate $\left(\mathrm{T}_{\text {plant-midday }}\right)$ and the water potential decrease between soil and leaf $\left(\Psi_{\text {soil }}-\Psi_{\text {leaf }}\right)_{\text {midday }}$

$$
\mathrm{K}_{\text {plant }}=\frac{\mathrm{T}_{\text {plant-midday }}}{\left(\Psi_{\text {soil }}-\Psi_{\text {leaf }}\right)_{\text {midday }}},
$$

where $\Psi_{\text {soil }}$ is the average soil water potential, which was assumed to equal the predawn $\Psi_{\text {leaf }}$ because $\Psi_{\text {soil }}$ remained relatively constant and came into equilibrium with the canopy water potential (Cole and Pagay, 2015; Jones, 2007). Therefore, midday $\Psi_{\text {soil }}$ values were estimated as predawn $\Psi_{\text {leaf }}$. $\mathrm{T}_{\text {plant-midday }}$ was determined as the ratio of weight changes to the total leaf area per plant at hourly intervals around midday, which has been described in detail in a previous study (Tsuda and Tyree, 2000).

The crop water stress index (CWSI) was temperatures of leaves and air by (Idso et al., 1981)

$$
\mathrm{CWSI}=\frac{\mathrm{dT}-\mathrm{dT}_{\min }}{\mathrm{dT}_{\max }-\mathrm{dT}_{\min }},
$$

where $\mathrm{dT}$ is the difference between canopy temperature $\left(\mathrm{T}_{\mathrm{c}}\right)$ and air temperature $\left(\mathrm{T}_{\mathrm{a}}\right)$, $\mathrm{T}_{\mathrm{c}}-\mathrm{T}_{\mathrm{a}} ; \mathrm{dT}_{\text {max }}$ is the upper limit of the canopyair temperature difference that can be reached under nonstressed conditions; and $\mathrm{dT}_{\min }$ is the lower limit of the canopy-air temperature difference under fully stressed conditions. The values for CWSI range from zero to one, where zero indicates no stress and one indicates maximum stress. The upper and

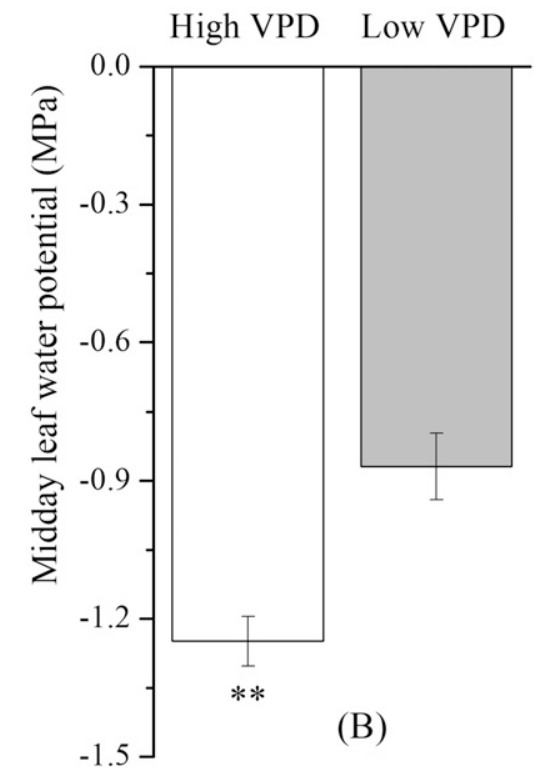
calculated as the difference between the

Fig. 1. Comparison of (A) predawn and (B) midday leaf water potential between low- and high-vapor pressure deficit (VPD) treatments. NS = nonsignificant. 


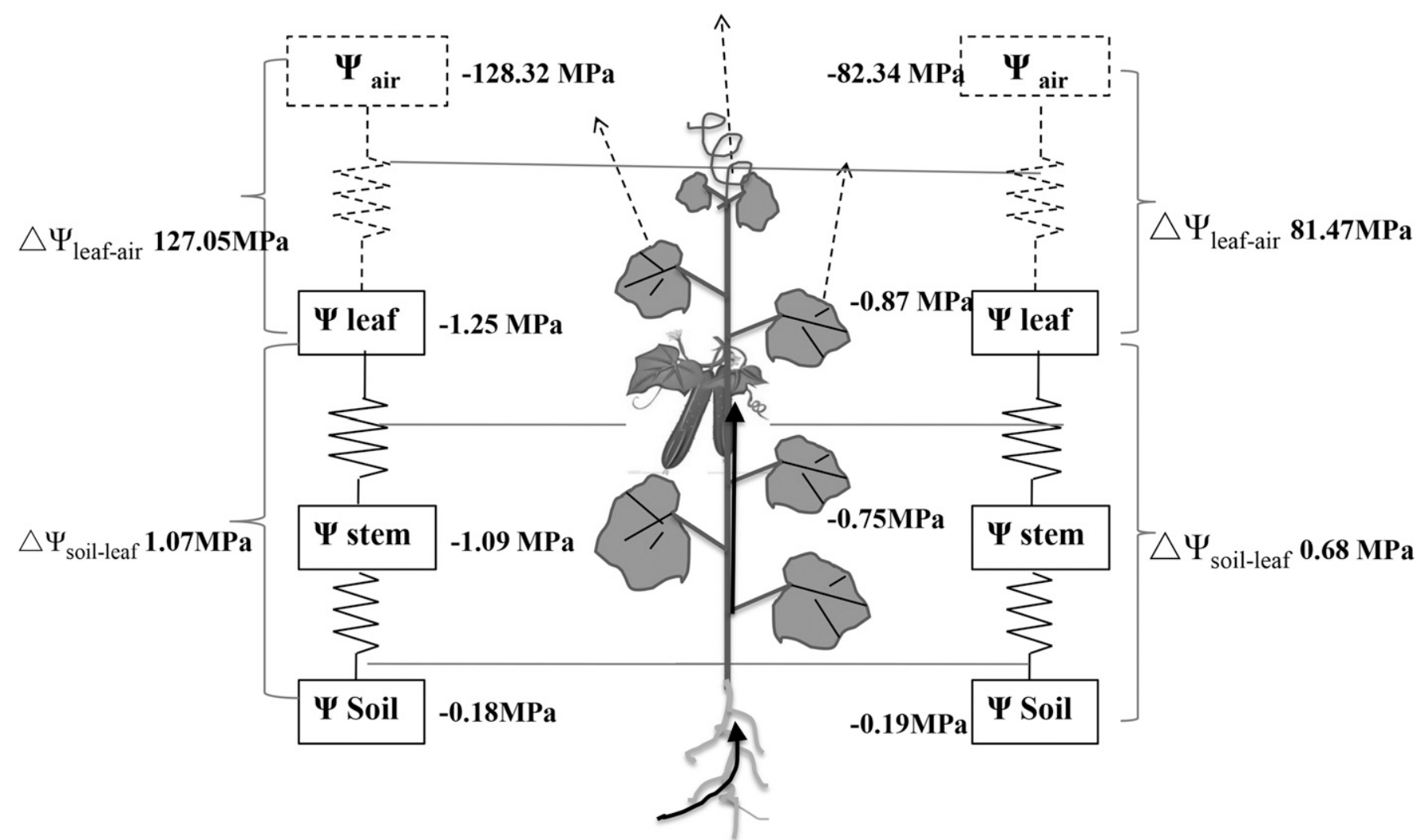

Water uptake and transport

Fig. 2. Effect of vapor pressure deficit (VPD) regulation on the energetic and hydraulic driving forces for water transport along the soil-plant-atmosphere continuum. Solid and dotted lines represent a series of pathways of water flow in liquid and vapor phases. $\Delta \Psi$ represents water potential drawdown between two compartments of the soil-plant-atmosphere continuum.

lower baselines of $\mathrm{dT}_{\max }$ and $\mathrm{dT}_{\min }$ were determined according to the relationship of the canopy-air temperature difference $\left(\mathrm{T}_{\mathrm{c}}-\mathrm{T}_{\mathrm{a}}\right)$ vs. VPD under nonstressed and fully stressed conditions, respectively, as described in detail in a previous study (Zhang et al., 2017). Leaf temperature was determined with a digital infrared thermometer (model GM320; Maizhe Co., Ltd, Shanghai, China) on seven healthy and mature leaves distributed randomly along the different layers of the canopy.

Determination of plant growth and morphological parameters. Plant samples were homogeneous for morphological criteria at the beginning of the experiment. The final morphological parameters were determined from the harvest. Plant biomass and leaf area were measured every $20 \mathrm{~d}$ after transplanting until fruits were harvested. Leaf area per plant was measured using an Li-3000 leaf area meter (LI-COR Inc.). Samples were dried at $80{ }^{\circ} \mathrm{C}$ to a constant weight and weighed.

Growth analysis parameters, including the relative growth rate (RGR), net assimilation rate (NAR) and leaf area ratio (LAR), were calculated from the total dry weight and leaf area using the equations (De Groot et al., 2001):

$$
\begin{aligned}
& \operatorname{RGR}=\left(\frac{1}{w}\right)\left(\frac{\Delta w}{\Delta t}\right)=\frac{\ln \left(w_{2}\right)-\ln \left(w_{1}\right)}{\left(t_{2}-t_{1}\right)} \\
& \mathrm{NAR}=\left(\frac{1}{L}\right)\left(\frac{\Delta w}{\Delta t}\right)=\frac{w_{2}-w_{1}}{t_{2}-t_{1}} \\
& \times \frac{\ln \left(L_{2}\right)-\ln \left(L_{1}\right)}{L_{2}-L_{1}} \\
& \mathrm{LAR}= \frac{L}{W}=\frac{\left(\frac{L_{1}}{W_{1}}+\frac{L_{2}}{W_{2}}\right)}{2}
\end{aligned}
$$

where $W_{1}$ and $W_{2}$ are the biomasses of whole plants at times $t_{1}$ and $t_{2}$, and $L_{1}$ and $L_{2}$ are the total leaf areas of whole plants at times $t_{1}$ and $t_{2} . t_{1}$ and $t_{2}$ were 20 and $40 \mathrm{~d}$ after transplanting in the current study, respectively.

Transpired water consumption and WUE. Whole-plant water use efficiency (WUE $E_{\text {plant }}$ ) was calculated as the ratio of the shoot biomass to the cumulative amount of water transpired (Kadam et al., 2015). The agronomic WUE (WUE yield $_{\text {) was calculated as }}$ the ratio of the fruit yield to the cumulative amount of water transpired (Reina-Sánchez et al., 2005).
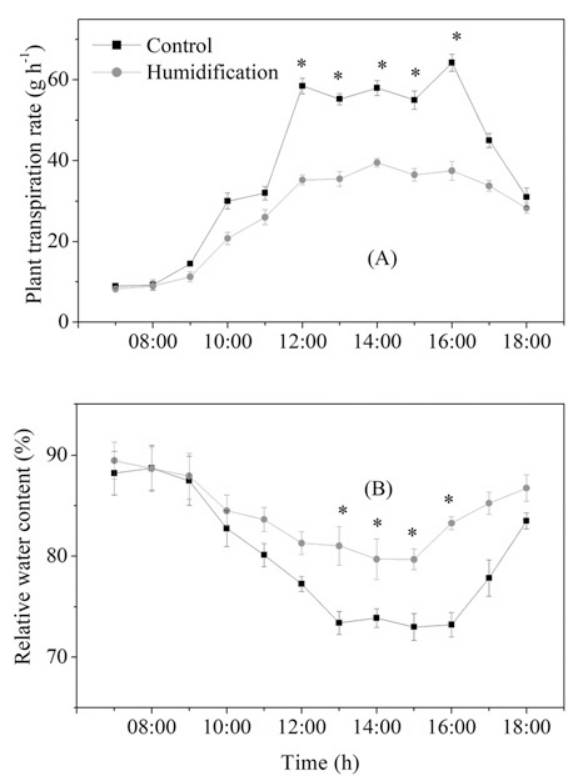

Fig. 3. Comparison of the typical diurnal variations in (A) plant transpiration and (B) leaf relative water content in the high- and low-vapor pressure deficit (VPD) treatments on a sunny day. Values are the means $\pm \operatorname{SE}(n=5)$. Significant differences between high- and low-VPD treatments were compared using Tukey's test. *,** Significant at $P<0.05$ or 0.01 , respectively. 
Statistical analysis. Data were subjected to analysis of variance using SAS version 9.1 (SAS Institute, Cary, NC).

\section{Results}

Energetic and driving forces for water movement. The meteorological data over the
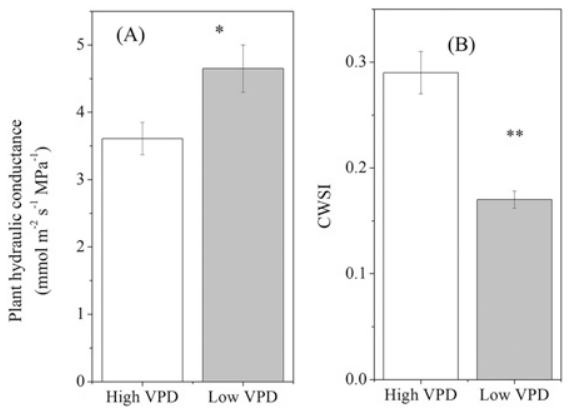

Fig. 4. Effect of vapor pressure deficit (VPD) regulation on (A) plant hydraulic conductance and (B) crop water stress index. Values are the means \pm SE $(n=10)$. Significant differences between the high- and low-VPD treatments were compared using Tukey's test. *, ** Significant at $P<0.05$ or 0.01 , respectively. CWSI $=$ crop water stress index.
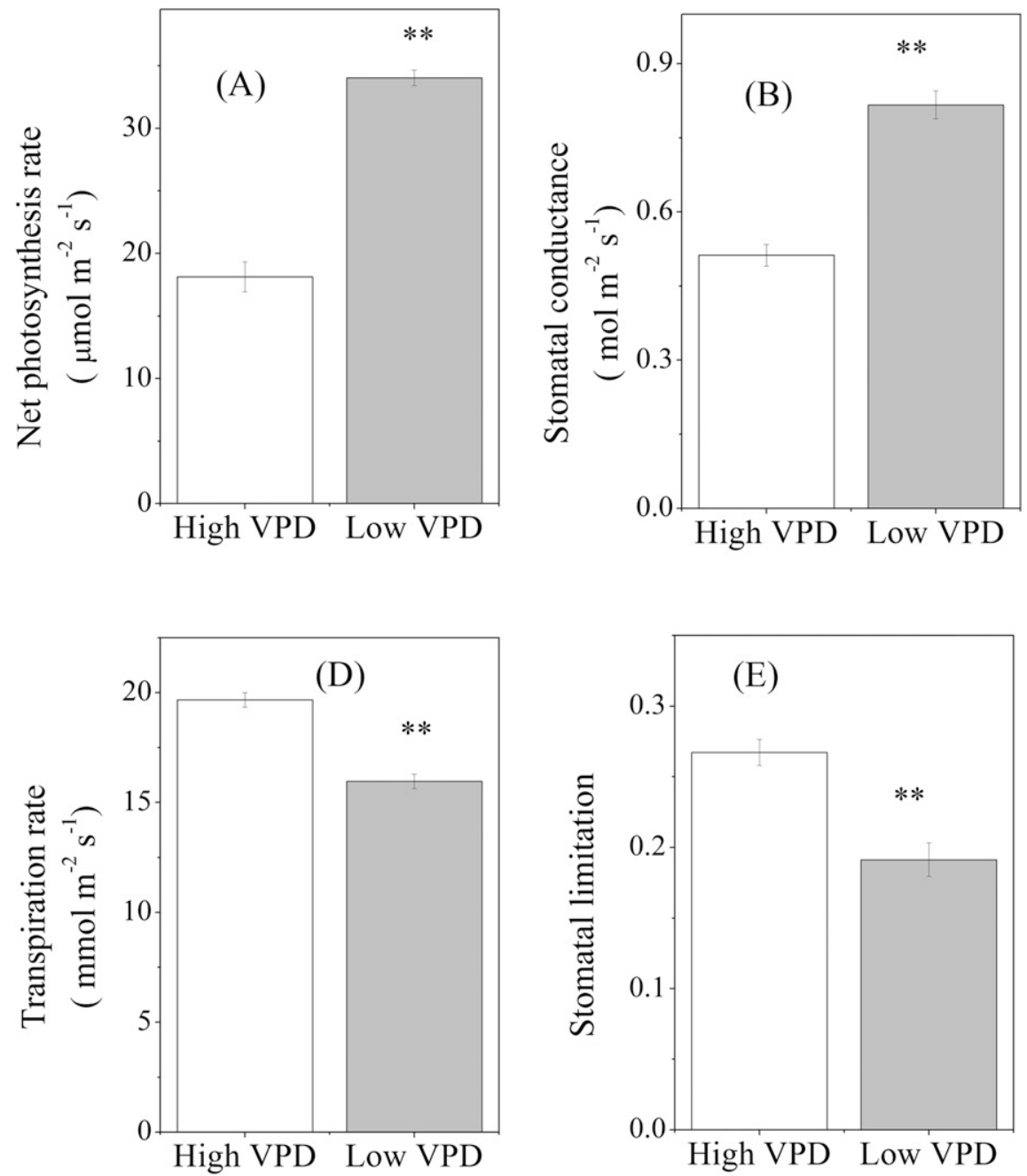

whole growing seasons are described in detail in Supplemental Table 1. Regulation of greenhouse VPD had great effects on the energetic and driving forces for water transport. Soil was maintained at a homogeneous water status between the two treatments, as indicated by a nonsignificant difference in predawn $\Psi_{\text {leaf }}$ (Fig. 1A). Midday $\Psi_{\text {leaf }}$ decreased in both the low- and high-VPD treatments, and this depression in midday $\Psi_{\text {leaf }}$ was moderated efficiently by reducing VPD (Fig. 1B). VPD control in relation to both energetic and driving forces for water transport is illustrated in Fig. 2. The driving force at the leaf-air boundary was the greatest along the soil-plant-atmosphere continuum and was reduced substantially in the low-VPD treatment (Fig. 2). Qualitatively, the water driving force at the leafatmosphere boundary can be 100-fold larger than that at the soil-leaf boundary.

Plant water status. Regulation of VPD by humidification had great effects on plantwater relations. Diurnal plant transpiration in the two VPD treatments followed similar transpiration rate decreased substantially in the low-VPD treatment, in which it was trends to those of Ta and VPD. The plant

reduced by $\approx 35 \%$ around midday (Fig. $3 \mathrm{~A}$ ). The diurnal leaf RWC in the two VPD treatments followed similar trends, with dramatic declines around midday (Fig. 3B). Leaf desiccation was moderated effectively by reducing VPD, and the leaf RWC was increased by $5 \%$ to $10 \%$ around midday (Fig. 3B). Plant hydraulic conductance increased significantly by $28.6 \%$ in the lowVPD treatment (Fig. 4A). Plants were less stressed in the low-VPD compartment compared with the high-VPD compartment, according to the value of the midday CWSI (Fig. 4B).

Leaf gas exchange. Reducing VPD increased significantly the photosynthesis rate, $g_{\mathrm{S}}$, and intercellular $\mathrm{CO}_{2}$ concentration (Fig. 5A-C). The leaf transpiration rate and Ls in the low-VPD treatment were reduced substantially by $26.1 \%$ and $39.7 \%$, respectively (Fig. 5D and E). Leaf InstWUE was increased substantially by reducing VPD (Fig. 5F).

Plant growth. Dry biomass of leaves was increased by $18.1 \%$ by reducing VPD, whereas dry biomass of leaves was unaffected by VPD regulation (Fig. 6A and B). Dry biomass of fruit was increased by $22.5 \%$ by
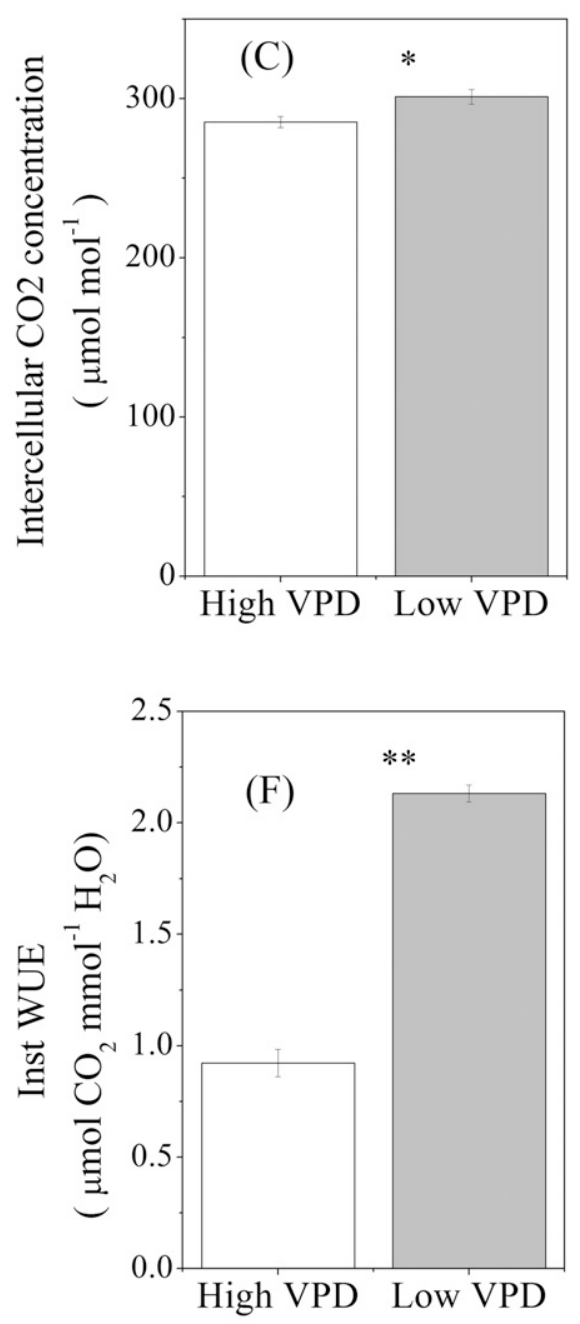

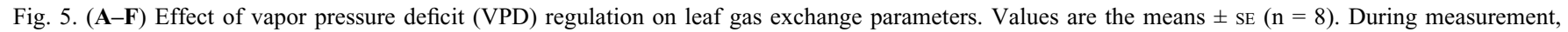
environmental conditions in the leaf chamber were set close to open-field conditions in the greenhouse. Significant differences between high- and low-VPD treatments were compared using Tukey's test. ${ }^{*},{ }^{*}$ Significant at $P<0.05$ or 0.01 , respectively. $\mathrm{CO}_{2}=$ carbon dioxide; WUE $=$ water-use efficiency. 
reducing VPD (Fig. 6C). Overall, reducing VPD increased shoot biomass significantly by $20.5 \%$ (Fig. $6 \mathrm{D}$ ).

Reducing VPD increased substantially RGR and NAR by $23.9 \%$ and $79.1 \%$, respectively (Fig. 7A and B). No significant difference in LAR was observed between the two treatments (Fig. 7C).

Fruit yield, water consumption, and WUE. The enhancement in plant growth by reducing VPD was accompanied by a substantial improvement in productivity. Reducing VPD increased the fruit yield per plant significantly by $20.1 \%$ (Fig. 8 A). Cumulative transpired water consumption was decreased significantly by $16.4 \%$ (Fig. $8 \mathrm{~B}$ ) in the lowVPD treatments. Along with the improvements in fruit yield and plant biomass, WUE $_{\text {yield }}$ and $\mathrm{WUE}_{\text {biomass }}$ were increased significantly by $43.1 \%$ and $40.5 \%$, respectively (Fig. 8C and D).

\section{Discussion}

Reducing excessive VPD decreased irrigation demand and moderated plant water stress by optimizing driving forces for water transport. Water transport through the soil-plantatmosphere continuum is a passive process driven by gradients of free energy. The driving force for water transport was determined by water potential gradients between the soil and the atmosphere $\left(\Delta \Psi=\Psi_{\text {soil }}-\right.$ $\left.\Psi_{\text {air }}\right)$. In natural conditions, soil moisture varies much less than the high-frequency evaporative demand (Caldeira et al., 2014). In addition to its high frequency, $\Psi_{\text {air }}$ reached an excessive negative value at midday in the current study. Consequently, the driving force for water transport was the greatest at the leaf-atmosphere boundary. Qualitatively, the water driving force at the leaf-atmosphere boundary can be 100 -fold larger than that at the soil-leaf boundary according to the experimental evidence.

Plant water deficit and physiological disorders occurred under the high VPD condition, despite plants being well irrigated. Experimental evidence demonstrated that evaporative demand generated excessive water driving force and plant water stress. Theoretical analysis in combination with experimental evidence highlighted the implications of VPD control in modulating water transport and improving plant water status. Maintaining optimum ranges of VPD was an efficient solution to reduce excessive atmospheric driving force for water loss, which was confirmed by the experimental evidence. Consequently, reducing the atmospheric driving force led to substantial reductions in the water flow rate and cumulative transpired water consumption in the current study. The transpiration rates of the leaf and the whole plant were reduced by different degrees in the current study, which can be attributed to the great environmental difference between the leaf chamber and greenhouse.

The mass balance between water supply and loss can be expressed as (MartínezVilalta et al., 2014; Roddy et al., 2016)
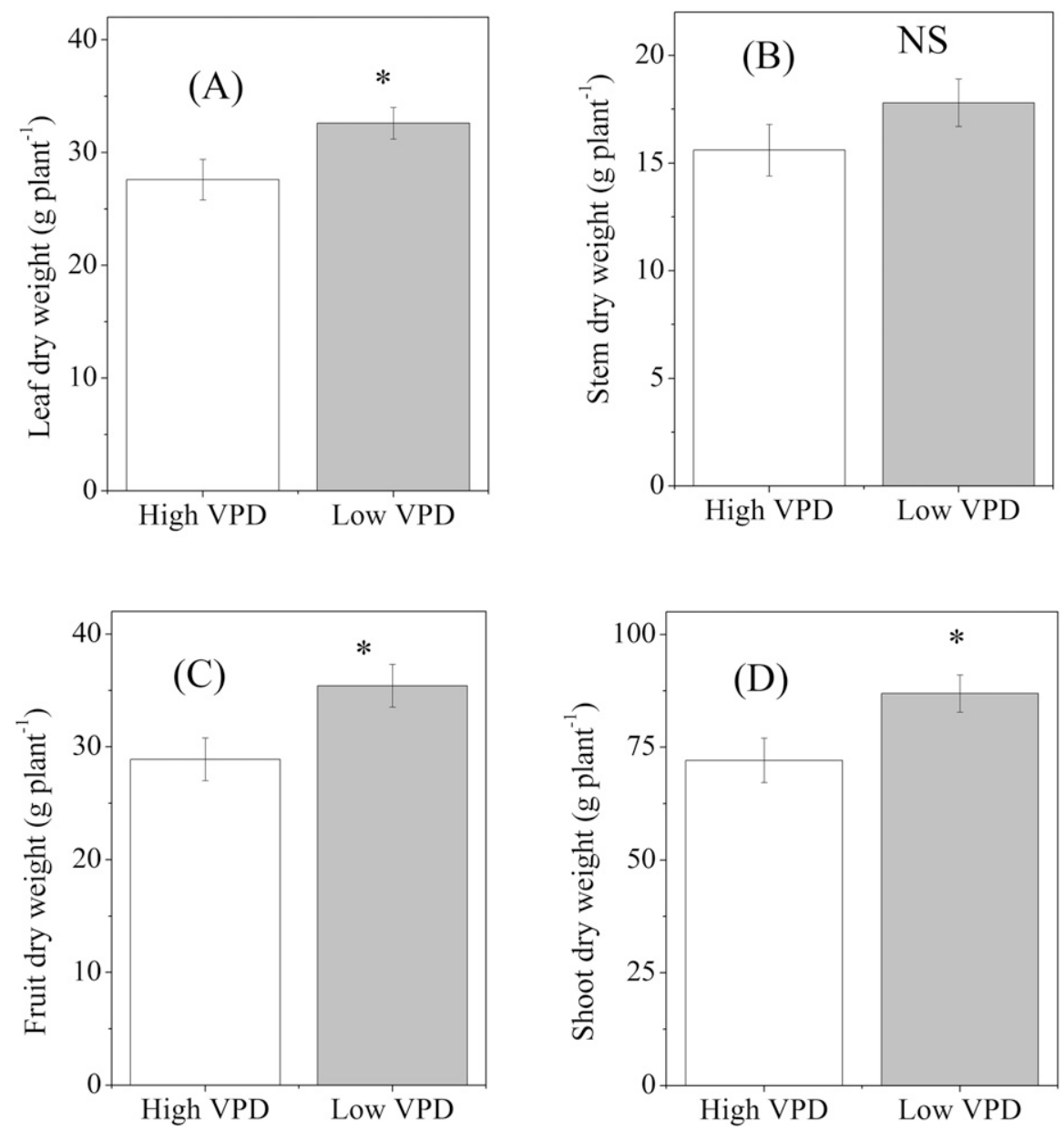

Fig. 6. Effect of vapor pressure deficit (VPD) regulation on biomass production of (A) leaf, $(\mathbf{B})$ stem, $(\mathbf{C})$ fruit, and (D) shoot. Values are means \pm SE $(n=10)$. Significant differences between high- and low-

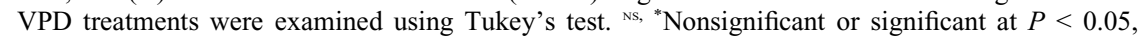
respectively.
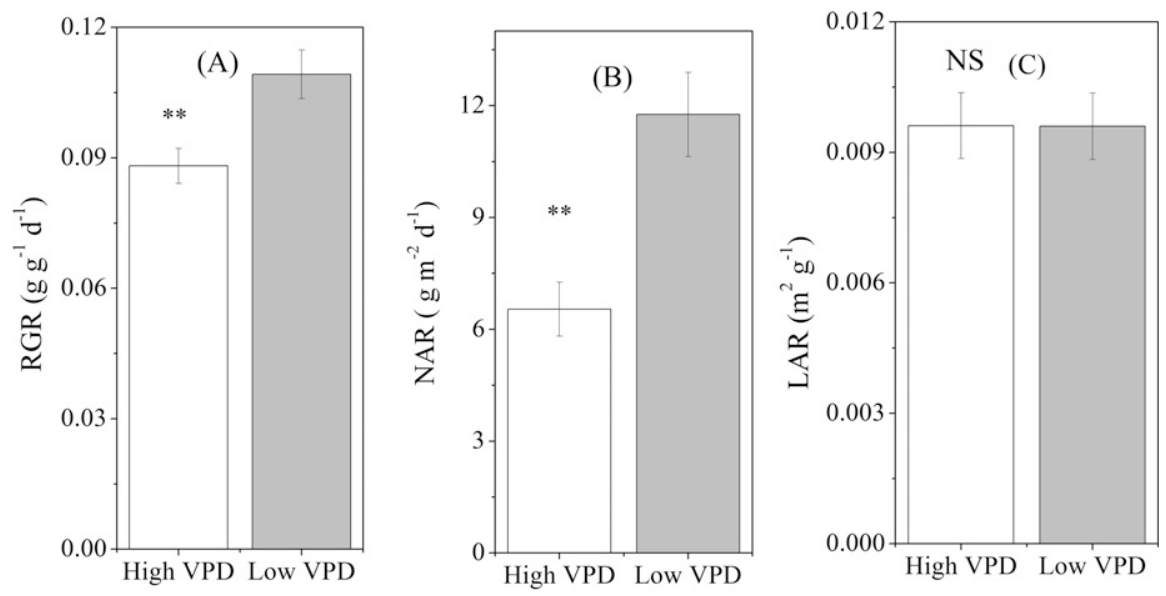

Fig. 7. Effect of vapor pressure deficit (VPD) regulation on plant growth parameters. (A) Relative growth rate (RGR), (B) net assimilation rate (NAR), and (C) leaf area ratio (LAR) were analyzed in plants sampled at 20 and $40 \mathrm{~d}$ after transplanting. Values are means $\pm \mathrm{SE}(\mathrm{n}=10)$. Significant differences between high- and low-VPD treatments were examined using Tukey's test. ${ }^{\mathrm{s},}$ " Nonsignificant or significant at $P<0.05$, respectively.

$$
\begin{aligned}
\Delta W= & J-E=k_{\text {plant }} \times\left(\Psi_{\text {soil }}-\Psi_{\text {leaf }}\right) \\
& -g_{s} \times V P D
\end{aligned}
$$

where $W$ is the water content, $J$ is water uptake and transport, $E$ is the water tran- spired loss, and $g_{\mathrm{S}}$ is canopy stomatal conductance.

If the mass balance of plant water is to be maintained, $J$ must equal $E$, and then $\Delta W=0$. Water balance is therefore of fundamental importance to maintain a physiologically 

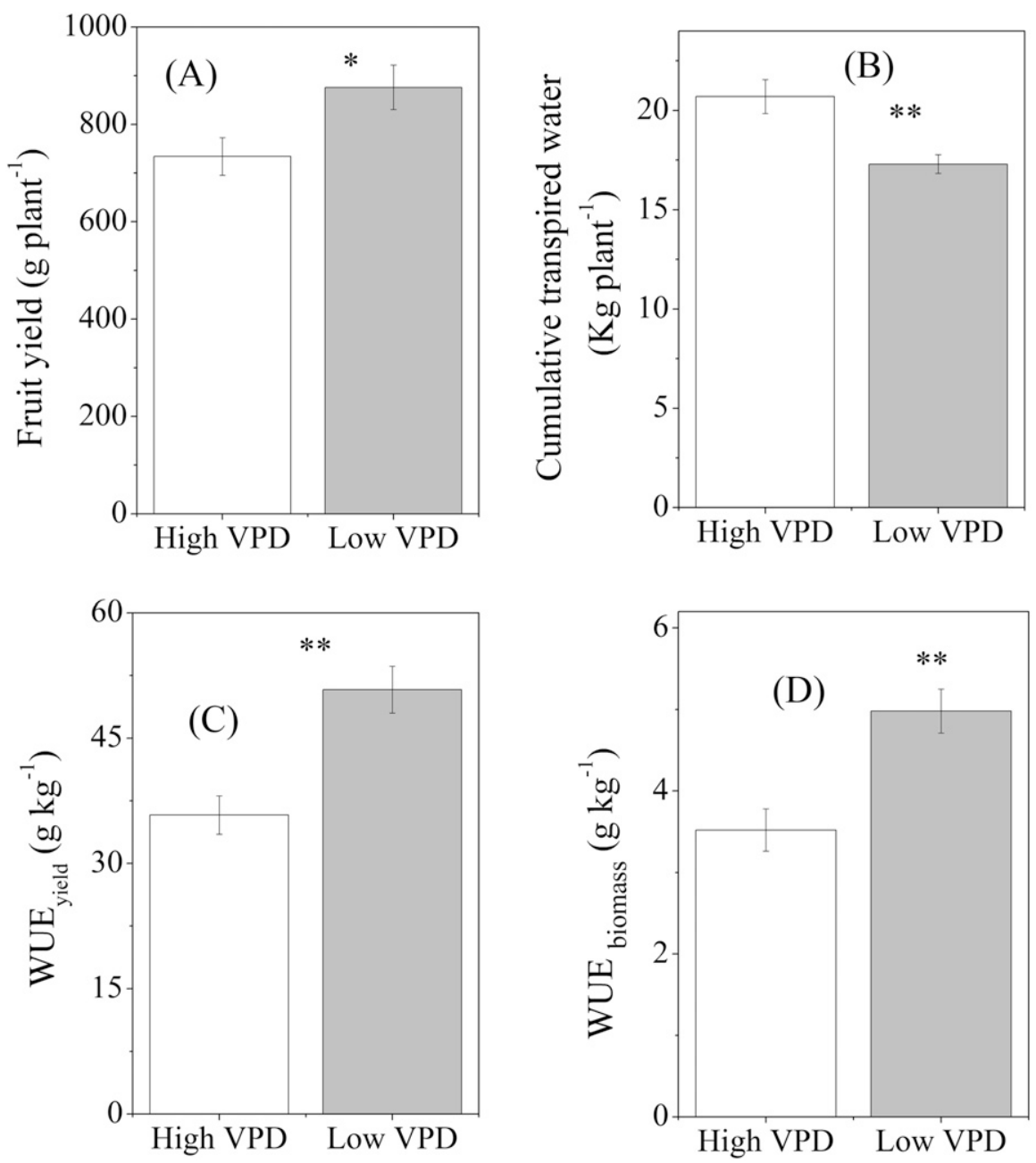

Fig. 8. Effect of vapor pressure deficit (VPD) regulation on (A) fruit yield, (B) cumulative transpired water consumption, (C) water-use efficiency (WUE) based on criteria of fruit yield, and (D) shoot biomass. Values are means \pm SE $(n=10)$. Significant differences between high- and low-VPD treatments were examined using Tukey's test. *, ** Significant at $P<0.05$ or 0.01 , respectively.

favorable water content and to avoid desiccation. Disruptions in the water balance and plant water stress were the foremost bottlenecks for crop productivity and were moderated efficiently by reducing VPD in the current study.

Reducing excessive VPD enhanced plant photosynthesis and productivity by improving plant water status. In addition to reducing water loss, enhancing carbon (biomass) production was also an efficient solution to improving physiologic WUE. Plant productivity processes such as plant growth, biomass, and yield production were improved by VPD regulation. Improvements in biomass and yield production can be attributed to the process of photosynthesis (Zhu et al., 2010). Even a small increase in the photosynthesis rate can translate into large improvements in biomass and yield, because carbon gain is integrated over the growing time and crop canopy (Parry et al., 2011). In the current experiment, the same numbers of nodes and fruit were retained for each plant. Therefore, the enhancement in fruit yield production under low-VPD conditions can be attributed to the increase in individual fruit weight. Growth analysis in combination with gas exchange parameters highlighted the significant role of VPD control in improving plant growth and productivity.

Reducing excessive VPD enhanced photosynthesis by sustaining stomatal function and improving plant water status. Ls of $\mathrm{CO}_{2}$ uptake was mitigated efficiently by VPD regulation in the current study. As mentioned, sustained stomatal function for $\mathrm{CO}_{2}$ uptake in the low-VPD treatment can be attributed to the maintenance of water balance and homeostatic water status. Stomatal closure in response to plant water deficit in vascular plants is believed to be a passive process driven by a reduction in turgor of the guard cells (Buckley, 2005). Because the turgor pressure of stomata is linked directly to plant water status, VPD manipulates the physical and physiological characteristics of guard cells by mediating water transport and affecting leaf hydration. VPD regulation maintains the water balance and relative homeostatic water status by coordinating the vapor loss and liquid supply, as described in Eq. [6]. Combined with a high leaf water potential, the turgor pressure of guard cells was sufficiently high to sustain pore openness for $\mathrm{CO}_{2}$ use in low-VPD-grown plants.
Comparison of water-productivity improving approaches that regulate atmospheric and soil water status. Water-saving irrigation techniques such as controlled, alternate partial root-zone irrigation and deficit irrigation have been widely recognized as important tools to increase WUE. In our study, WUE improved significantly as a result of a substantial reduction in the loss of transpired water, with no significant reduction in yield production. In the current study, a reduction in transpired water consumption and an improvement in plant productivity were achieved simultaneously by regulating atmospheric VPD. WUE based on the criteria of plant biomass and fruit yield was increased by reducing VPD. Considering the trade-off between water loss and carbon gain, the current study suggests that regulating atmospheric VPD had an advantage over watersaving irrigation techniques. This theoretical analysis needs further experimental comparisons between the two techniques.

Although the implication of VPD control in improving WUE was highlighted by theoretical analysis and experimental evidence, VPD regulation faced dilemmas when the theory was applied in agricultural practice. Mechanical application systems such as the pad-fan system or the fogging system were necessary to facilitate VPD control, which required extra investment. In addition to plant-transpired water consumption, the application of fogging for VPD regulation also accounted for agricultural water consumption in greenhouse production. Water savings and WUE improvement over experimental periods will be counterbalanced to some extent by the fogging water. Although low VPD improved cucumber growth and productivity, the negative effect of low VPD was not considered in the current study. Many lines of evidence were provided to indicate that a low VPD reduced the driving force for nutrient uptake and transport, which is especially likely to cause calcium deficiency (Bakker, 1990). In addition, the germination of fungal pathogen spores increases and diseases spread rapidly when VPD is low. Nutritional deficiencies and disease epidemics will affect fruit quality negatively.

The evaluation of environmental control must be based on economic considerationsthe best balance between the net profit increase and systems investment. To reduce bottlenecks limiting physiological productivity and economic efficiency, a holistic view of greenhouse environmental regulation is required that incorporates a trade-off between carbon gain and water consumption, yield increase, and fruit quality.

\section{Conclusions}

Reducing excessive VPD improved the WUE of cucumber by balancing the tradeoff between water consumption and plant productivity. Reducing excessive VPD had significant implications for reducing atmospheric water driving forces, which reduced significantly the water flow rate and cumulative 
plant transpiration. The reduction in excessive water loss moderated plant water stress efficiently, as leaf hydration, hydraulic limitation, and excessive negative water potential were prevented by maintaining water balance in the low-VPD treatment. The moderation of water stress by reducing VPD sustained stomatal function for photosynthesis and plant growth, which increased fruit yield and shoot biomass substantially. Reduced transpiration in combination with improved plant productivity contributed to a substantial increase in WUE based on the criteria of plant biomass and fruit yield.

\section{Literature Cited}

Attia, Z., J.C. Domec, R. Oren, D.A. Way, and M. Moshelion. 2015. Growth and physiological responses of isohydric and anisohydric poplars to drought. J. Expt. Bot. 66:4373-4381.

Bakker, J. 1990. Effects of day and night humidity on yield and fruit quality of glasshouse tomatoes (Lycopersicon esculentum Mill.). J. Hort. Sci. 65:323-331.

Buckley, T.N. 2005. The control of stomata by water balance. New Phytol. 168:275-292.

Caldeira, C.F., M. Bosio, B. Parent, L. Jeanguenin, F. Chaumont, and F. Tardieu. 2014. A hydraulic model is compatible with rapid changes in leaf elongation under fluctuating evaporative demand and soil water status. Plant Physiol. 164:1718-1730.

Cole, J. and V. Pagay. 2015. Usefulness of early morning stem water potential as a sensitive indicator of water status of deficit-irrigated grapevines (Vitis vinifera L.). Scientia Hort. 191:10-14.

De Groot, C.C., L.F.M. Marcelis, R. Van den Boogaard, and H. Lambers. 2001. Growth and dry-mass partitioning in tomato as affected by phosphorus nutrition and light. Plant Cell Environ. 24:1309-1317.

Deng, X., L. Shan, H. Zhang, and N.C. Turner. 2006. Improving agricultural water use efficiency in arid and semiarid areas of China. Agr. Water Mgt. 80:23-40.

Duan, Q., W. Jiang, M. Ding, Y. Lin, and D. Huang. 2014. Light affects the chloroplast ultrastructure and post-storage photosynthetic performance of watermelon (Citrullus lanatus) plug seedlings. PLoS One 9(10): 111165.
Fricke, W. 2016. Water transport and energy. Plant Cell Environ. 40:977-994.

Gheysari, M., S.-H. Sadeghi, H.W. Loescher, S. Amiri, M.J. Zareian, M.M. Majidi, P. Asgarinia, and J.O. Payero. 2017. Comparison of deficit irrigation management strategies on root, plant growth and biomass productivity of silage maize. Agr. Water Mgt.. 182:126-138.

Idso, S.B., R.D. Jackson, P.J. Pinter, Jr., R.J. Reginato, and J.L. Hatfield. 1981. Normalizing the stress-degree-day parameter for environmental variability. Agr. Meteorol. 24:45-55.

Iraqi, D., S. Gagnon, S. Dubé, and A. Gosselin. 1995. Vapor pressure deficit (VPD) effects on the physiology and yield of greenhouse tomato. HortScience 30:846.

Jones, H.G. 2007. Monitoring plant and soil water status: Established and novel methods revisited and their relevance to studies of drought tolerance. J. Expt. Bot. 58:119-130.

Kadam, N.N., X. Yin, P.S. Bindraban, P.C. Struik, and K.S. Jagadish. 2015. Does morphological and anatomical plasticity during the vegetative stage make wheat more tolerant of waterdeficit stress than rice? Plant Physiol. 167: 1389-1401.

Kang, S. and J. Zhang. 2004. Controlled alternate partial root-zone irrigation: Its physiological consequences and impact on water use efficiency. J. Expt. Bot. 55:2437-2446.

Katsoulas, N., A. Baille, and C. Kittas. 2001. Effect of misting on transpiration and conductances of a greenhouse rose canopy. Agr. For. Meteorol. 106:233-247.

Lu, N., T. Nukaya, T. Kamimura, D. Zhang, I. Kurimoto, M. Takagaki, T. Maruoa, T. Kozaia, and W. Yamori. 2015. Control of vapor pressure deficit (VPD) in greenhouse enhanced tomato growth and productivity during the winter season. Scientia Hort. 197:17-23.

Martínez-Vilalta, J., R. Poyatos, D. Aguadé, J. Retana, and M. Mencuccini. 2014. A new look at water transport regulation in plants. New Phytol. 204:105-115.

Parry, M.A., M. Reynolds, M.E. Salvucci, C. Raines, P.J. Andralojc, X.G. Zhu, G.D. Price, A.G. Condon, and R.T. Furbank. 2011. Raising yield potential of wheat: II. Increasing photosynthetic capacity and efficiency. J. Expt. Bot. 62:453-467.

Reina-Sánchez, A., R. Romero-Aranda, and J. Cuartero. 2005. Plant water uptake and water use efficiency of greenhouse tomato cultivars irrigated with saline water. Agr. Water Mgt. 78:54-66.

Roddy, A.B., C.R. Brodersen, and T.E. Dawson. 2016. Hydraulic conductance and the maintenance of water balance in flowers. Plant Cell Environ. 39:2123-2132.

Simonin, K.A., E. Burns, B. Choat, M.M. Barbour, T.E. Dawson, and P.J. Franks. 2014. Increasing leaf hydraulic conductance with transpiration rate minimizes the water potential drawdown from stem to leaf. J. Expt. Bot. 66:1303-1315.

Tsuda, M. and M.T. Tyree. 2000. Plant hydraulic conductance measured by the high pressure flow meter in crop plants. J. Expt. Bot. 345:823-828

Wheeler, T.D. and A.D. Stroock. 2008. The transpiration of water at negative pressures in a synthetic tree. Nature 455:208-212.

Xu, Z. and G. Zhou. 2008. Responses of leaf stomatal density to water status and its relationship with photosynthesis in a grass. J. Expt. Bot. 59:3317-3325.

Yang, H., T. Du, R. Qiu, J. Chen, F. Wang, Y. Li, C. Wang, L. Gao, and S. Kang. 2017. Improved water use efficiency and fruit quality of greenhouse crops under regulated deficit irrigation in northwest China. Agr. Water Mgt. 179:193204.

Zhang, D., Q. Du, Z. Zhang, X. Song, X. Jiao, and J. Li. 2017. Vapour pressure deficit control in relation to water transport and water productivity in greenhouse tomato production during summer. Sci. Rep. 7:43461.

Zhang, D., X. Jiao, Q. Du, X. Song, and J. Li. 2018. Reducing the excessive evaporative demand improved photosynthesis capacity at low costs of irrigation via regulating water driving force and moderating plant water stress of two tomato cultivars. Agr. Water. Mgt. 199:22-33.

Zhang, D., Z. Zhang, J. Li, Y. Chang, Q. Du, and T. Pan. 2015. Regulation of vapor pressure deficit by greenhouse micro-fog systems improved growth and productivity of tomato via enhancing photosynthesis during summer season. PLoS One 10:e133919.

Zhu, X.G., S.P. Long, and D.R. Ort. 2010. Improving photosynthetic efficiency for greater yield. Annu. Rev. Plant Biol. 61:235-261.

Zsögön, A., A.C. Negrini, L.E. Peres, H.T. Nguyen, and M.C. Ball. 2015. A mutation that eliminates bundle sheath extensions reduces leaf hydraulic conductance, stomatal conductance and assimilation rates in tomato (Solanum lycopersicum). New Phytol. 205:618-626. 
Supplemental Table 1 . The average daily meteorological data inside the greenhouse during growing period.

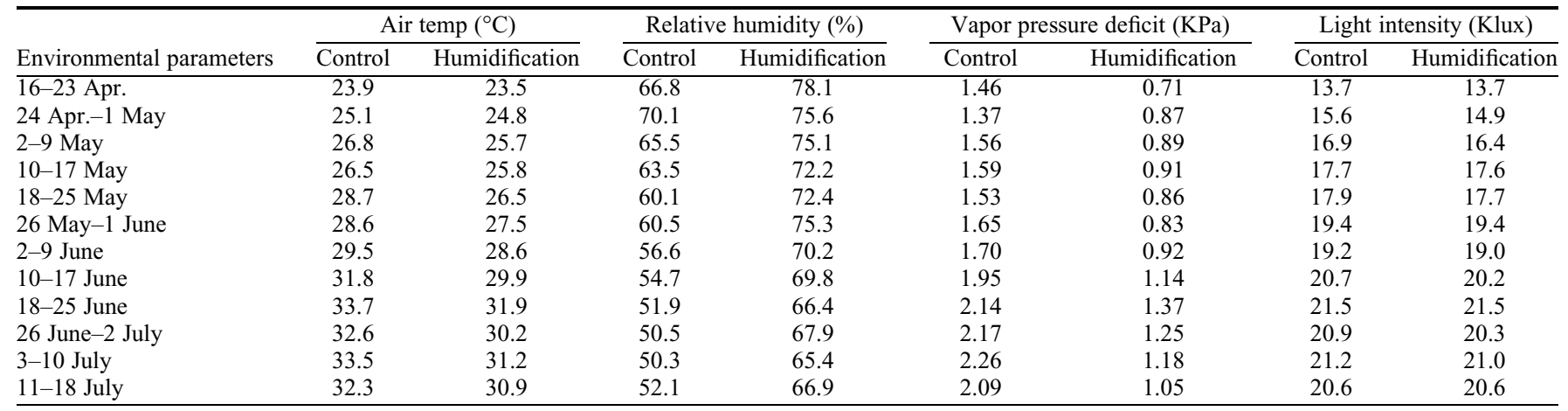

